\title{
La fisura irremediable: la nación peruana en la obra de Mario Vargas Llosa ${ }^{40}$
}

\section{The irreparable fissure: the Peruvian nation in the works of Mario Vargas Llosa}

\author{
María Mercedes Ortiz \\ Recibido: 1 de Agosto 2011. Aprobado: 20 de Septiembre 2011
}

\begin{abstract}
Resumen
Leídas en conjunto, las novelas La casa verde (1967), El hablador (1987) y Lituma en los Andes (1993), de Mario Vargas Llosa, nos revelan una nación deseada e imaginada como mestiza y homogénea, puesta al servicio de los intereses neoliberales en un mundo globalizado. Las obras se ocupan de la Selva y los Andes o Sierra, y sus poblaciones indígenas, tradicionalmente excluidas de la nación peruana, y de las relaciones de estas regiones con la Costa, el centro de poder político del país. Al romper los límites entre las novelas mediante la circulación de personajes e historias comunes y al crear personajes indígenas dotados de cierta voz, Vargas Llosa pareciera querer abolir la tradicional separación entre las distintas regiones del Perú, prefigurando de este modo un proyecto de nación inclusivo que dé participación a los permanentemente excluidos.
\end{abstract}

Palabras clave: Mario Vargas Llosa; La casa verde; El hablador; Lituma en los Andes ; Peruvian novel

\begin{abstract}
Read together, the novels La casa verde (1967), El hablador (1987) and Lituma en los Andes (1993), Mario Vargas Llosa, reveal a desired and imagined as mestizo nation and homogeneous, in the service of the interests neoliberal in a globalized world. Works dealing with the jungle and the Andes or Sierra, and traditionally excluded from the Peruvian nation, and the relationship of these regions to the coast, the center of political power in the country's indigenous peoples. By breaking the boundaries between the novels by circulating common characters and stories and creating characters of certain indigenous gifted voice, Vargas Llosa seems to want to abolish the traditional separation between the different regions of Peru, thus foreshadowing a draft inclusive nation give participation to permanently excluded.
\end{abstract}

Keywords: Mario Vargas Llosa; La casa verde; El hablador; Lituma en los Andes; Peruvian novel.

A través de las historias de algunos personajes que se mueven a lo largo y ancho de la geografía nacional, como el sargento Lituma que aparece en La casa verde y en Lituma

40 Ensayo de sistematización realizado por la autora en el marco de sus investigaciones sobre la literatura latinoamericana. 
en los Andes, el autor logra captar una serie de fenómenos sociales que han logrado romper en las últimas décadas en Perú con el aislamiento regional, tales como el narcotráfico, la emergencia del grupo guerrillero Sendero Luminoso y las migraciones desde los Andes hacia la costa y la selva. Estas transformaciones no implican, sin embargo, que los indígenas hayan entrado en pie de igualdad en la nación y la sociedad, ya que, en últimas, Vargas Llosa revive y reutiliza en estos nuevos contextos culturales y sociales toda una gama de imaginarios discriminatorios que históricamente han sustentado las posiciones excluyentes de las elites criollas hacia los grupos indígenas amazónicos y los campesinos quechuas.

El mundo que refrendan estas novelas, no obstante, se encuentra en un proceso de desmoronamiento debido a que ha venido sufriendo una pérdida paulatina de poder social. Al respecto, Peter Flindell Klarén plantea que tal fenómeno obedece a la pérdida de control de la antigua oligarquía, a la emergencia de las mujeres como figuras centrales en los movimientos sociales y la política y a que las clases y grupos subalternos, suprimidos y manipulados por largo tiempo, han estampado su huella, no sólo en la cultura del Perú, sino en sus instituciones y posibilidades futuras (xv). Desde esta perspectiva, los mensajes contenidos en la narrativa de Vargas Llosa serían, al presente, mensajes residuales de un mundo en extinción.

\section{Una topografía moral}

Perú ha sido, por tradición, una nación estructurada alrededor de la costa o núcleo “civilizado" del país. La Sierra y la selva, por el contrario, han sido excluidas de la misma y esta última región, en particular, ha sido situada en el imaginario hegemónico allende las fronteras de la civilización. Dentro de esta topografía moral, noción que tomo de Michael Taussig, la Sierra que constituye una frontera interior en términos étnicos y culturales, goza, sin embargo, del prestigio de una ocupación milenaria y del glorioso pasado incaico, así se menosprecie y margine al campesinado quechua actual. ${ }^{41}$ Además, desde la visión geográfica, Perú ha sido definido como un país andino. Las tierras

\footnotetext{
${ }^{41}$ En el capítulo 18 de Shamanism, Colonialism and the Wild Men (1987), Taussig desarrolla la idea del paisaje como una construcción histórica, social y política dentro de la cual se le asignan valores diferenciados a las distintas regiones de un país. En el caso de Colombia, que es el que analiza, el "infierno tropical de la selva y sus habitantes" se opone al "paraíso terrestre" de las montañas de los Andes (292).
} 
selváticas, a pesar de que ocupan un 60\% del ámbito peruano y fueron probablemente el lugar de origen de la civilización andina, han sido concebidas en los imaginarios dominantes como la región más marginal del país (Flindell Klarén, 4). Hacia mediados del siglo XIX, la selva era un territorio ignoto, una tierra por conquistar ocupada por grupos indígenas cuya historia y culturas se ignoraban y a los cuales se consideraba salvajes por excelencia.

El Estado peruano sólo se interesó por aquella tras la Guerra del Pacifico con Chile (1879-1884), al menos, teóricamente, como una esperanza para el futuro de la nación (Santos-Granero y Barclay, 59). Entre 1880 y 1920, la Amazonia, en toda su extensión, fue sometida a una frenética extracción de caucho —el así llamado boom del caucho-a fin de satisfacer la necesidad que de esa materia prima tenían los países industrializados del momento. El boom trajo consigo epidemias, esclavitud y muerte para los grupos selváticos del Perú, en particular para los de la actual Región Madre de Dios. A partir de esta catastrófica experiencia, diversas comunidades selváticas tomaron la decisión de vivir aisladas, evitando todo contacto con la sociedad nacional (Huertas Castillo 21, 29). Durante los dos períodos de gobierno de Fernando Belaúnde Terry (1964-1968 y 19801985) se impulsaron proyectos tendientes a integrar la Selva alta (montaña) y la Selva baja a la economía del país ya que esta región se veía como la panacea a los problemas agrarios de la Sierra y como la despensa que podría alimentar a los peruanos. En consecuencia, se iniciaron planes de colonización y la construcción de vías de acceso a aquella, como la Carretera Marginal de la Selva (Rosengren 47). Miles de campesinos andinos sin tierra se lanzaron a la región, afectando gravemente al ecosistema y a los grupos indígenas que allí vivían, cuyos territorios no estaban protegidos legalmente (Chirif 57-61).

En el caso de la Sierra, después de la independencia de España, la gran mayoría indígena que habitaba en esta región permaneció excluida de la nueva república (Flindell Klarén 136). La novel nación evolucionó así como una nación dividida de manera tajante, tanto geográfica, como económica y culturalmente, entre Costa y Sierra, y al interior de la cual, según Alberto Flores Galindo, era imposible la comunicación entre la clase alta, la oligarquía de comerciantes, banqueros y modernos terratenientes de la Costa y los 
campesinos andinos. En sus palabras: "La búsqueda de un consenso nacional era imposible" (229).

Después de una época de intensas pero fallidas rebeliones de los campesinos indígenas en la Sierra, durante la segunda década del siglo XX, el orden imperante en la región empezó a tambalearse hacia los años sesenta en la medida que los campesinos serranos comenzaron a exigir tierras, escuelas y pago salarial y los colonos de las haciendas se sublevaron, organizados en sindicatos. Ambos grupos llevaron a cabo invasiones de tierras cada vez más frecuentes y masivas y como consecuencia de esta agitación agraria el poder de los terratenientes, y en general de los poderes locales de la Sierra, se debilitó (Galindo 300-318). En 1968, los militares peruanos, cansados de la ineficacia del gobierno de Belaúnde Terry para llevar a cabo las reformas que el país necesitaba con urgencia, y alarmados por el reciente surgimiento de grupos guerrilleros que seguían el modelo de la Revolución cubana, se tomaron el poder bajo el mando del general Juan Velasco Alvarado, quien gobernó hasta 1975 (Flindell Klarén 336-340).

Bajo su gobierno, se llevó a cabo una reforma agraria que afectó un $60 \%$ de las tierras agrícolas del país; los más beneficiados fueron, sin embargo, los campesinos de las haciendas de la Costa (un 10\% del campesinado total). Sus contrapartes, los comuneros y colonos de la Sierra, poco o nada ganaron con la reforma y por ello apoyaron en la década de los ochenta al grupo insurgente Sendero Luminoso (Flindell Klarén 342). Velasco se ocupó también de la selva y en 1974 promulgó la Ley de Comunidades Nativas que reglamentaba los derechos de los indígenas de la Amazonia peruana a sus territorios, ley que sin embargo dejó un ancho margen para la futura colonización de esta región. Los gobernantes que sucedieron a Velasco se han preocupado de facilitar la inversión de grandes capitales en la Amazonia peruana con la finalidad de integrarla lo más rápidamente posible a la economía de un mercado globalizado (Rosengren 48-50). Este conflicto agrario, que afectó profundamente las estructuras económicas, sociales, políticas y culturales del Perú, aparece de manera tangencial o no figura en absoluto en las tres obras de las que me ocupo en este ensayo. La casa verde, en la que la costa y la selva se imbrican gracias a la historia de la pareja conformada por el sargento Lituma, oriundo de la ciudad costera de Piura, y Bonifacia, una indígena aguaruna de la Selva alta, permanece totalmente al margen de la problemática agraria ya que la narración se

Poligramas 36, segundo semestre 2011, ISSN 0120-4130. 
sitúa durante la Segunda Guerra Mundial, época en la cual se produjo un segundo y efímero boom del caucho debido a que los Aliados, dada su imposibilidad de acceder al látex asiático, demandaron el del Amazonas según señala M.J. Fenwick (59).

En el caso de El hablador, obra que trata de la suerte de los matsigenka, un grupo arahuaco de la Selva alta peruana, se menciona la llegada de colonos serranos a los territorios de estos indígenas, sin embargo, la novela sólo menciona brevemente el problema agrario en la Sierra que precipitó esta colonización, la cual, junto con otras empresas económicas impulsadas por el Estado, como la explotación de maderas y de petróleo, ha puesto en peligro la existencia, no sólo de los matsigenka sino de otros grupos indígenas.

Lituma en los Andes se desenvuelve en la parte sur de la Sierra central, subregión a la que los limeños denominan despectivamente La Mancha India (Flindell Klarén 370). Publicada en 1993, es la más reciente de las tres novelas y se desarrolla en la década de los ochenta del siglo $\mathrm{XX}$, durante el apogeo del movimiento guerrillero Sendero Luminoso, agrupación que juega un rol importante en la obra. Para tratar de entender un fenómeno como el de esta guerrilla, Vargas Llosa desdeña por completo el relacionarlo con el conflicto agrario que ha marcado la historia contemporánea peruana y apela, sin la menor reflexión histórica, a la explicación de una supuesta barbarie intrínseca a las culturas andinas y selváticas como fundamento último de la existencia del grupo guerrillero y de la violencia que azotó al Perú en la década de los ochenta y de los noventa del siglo pasado.

Las tres novelas muestran, por el contrario, la gran capacidad que Vargas Llosa posee para revitalizar y reutilizar los imaginarios que han sustentado y justificado, desde los albores de la conquista europea, la opresión de los indios en América Latina. En estas obras la selva, la Sierra y sus poblaciones indígenas son presentadas a partir de enfoques diferentes y no es fácil descifrar los mensajes discriminatorios que estas obras encierran, puesto que aparecen enmascarados bajo las brillantes técnicas narrativas del autor, las cuales han engañado a muchos que lo han visto como un defensor de los indígenas. 


\section{Desiertos civilizados y selvas sin historia}

En Historia secreta de una novela (1971), publicada cinco años después de La casa verde, Vargas Llosa hace una reflexión a posteriori de la génesis de la novela en la que devela los parámetros evolucionistas y el manejo del tiempo que animaron su proceso creativo. Explica así que La Casa Verde fue concebida, ante todo, como el movimiento entre dos polos opuestos de desarrollo, la ciudad costera de Piura y la minúscula factoría amazónica de Santa María de Nieva:

Piura es el desierto, el color amarillo, el algodón, el Perú español, "la civilización." Santa María de Nieva es la selva, la exuberancia vegetal, el color verde, tribus que no han entrado a la historia, instituciones y costumbres que parecen supervivencias medievales. (9)

Aunque el autor ironiza un poco al poner civilización entre comillas, y en la novela muestra que hay lugares en Piura como el barrio de la Mangachería, que no se ajustan precisamente a lo que se considera progreso y modernidad, la cita anterior, imbuida de una notoria tendencia hispanizante, privilegia una perspectiva o visión de la nación gestada desde el centro y caracterizada por un marcado etnocentrismo puesto que cataloga de bárbaro todo lo que se diferencia de ella.

Vargas Llosa coloca asimismo a los indígenas selváticos en otro tiempo, en este caso la prehistoria, ya que más adelante habla de un Perú de la Edad de Piedra. El escritor utiliza aquí una idea que el antropólogo Johannes Fabian ha desarrollado como el concepto de "negación de la contemporaneidad (denial of coevalness), una tendencia mediante la cual la antropología se ha permitido colocar a las culturas que estudia en un tiempo distinto al presente del investigador, concibiéndolas como "primitivas," "campesinas," "tribales" o "subdesarrolladas". De este modo, liga su práctica con situaciones de dominación colonial o neocolonial $(30-31,96) .{ }^{42}$ Esta noción impregna no sólo la narrativa de Vargas Llosa sino que ha circulado tradicionalmente entre los sectores que detentan el poder en

\footnotetext{
${ }^{42}$ I will call it denial of coevalness. By that I mean a persistent and systematic tendency to place the referent $(s)$ of anthropology in a Time other than the present of the producer of anthropological discourse (31) (en itálica en el original). (La voy a llamar negación de la contemporaneidad. Con ello quiero significar una persistente y sistemática tendencia a colocar el /los referente(s) de la antropología en un Tiempo distinto al del presente del productor del discurso antropológico) (mi traducción).
} 
Perú, quienes han justificado así la necesidad imperiosa de "civilizar" a los indígenas para rescatarlos de su barbarie e incorporarlos a la nación.

Entre estos sectores se destaca la iglesia católica. Andrés Ferrero, un misionero dominico que trabajó activamente en pro de la evangelización de los matsigenka, publicó en 1967 un libro titulado Los machiguengas: tribu selvática del sur-oriente peruano, en el cual los presenta como seres arcaicos, primitivos e infantiles. ${ }^{43}$ En la introducción a esta obra, que fue una de las fuentes consultadas por Vargas Llosa para escribir El hablador, el Obispo titular de Bapara invita a los lectores a conocer a los matsigenka cual la imagen viviente de nuestro propio pasado: "Y así como al ver a un niño tenemos delante un retrato más o menos fiel de nuestro ayer, en la vida de un pueblo primitivo encontramos la imagen de aquel del que nosotros venimos (8). La negación de la contemporaneidad de los indígenas es contundente en estas frases que justifican la labor evangelizadora de la iglesia y su concomitante destrucción de las culturas indígenas.

Incluso prominentes políticos, como Víctor Raúl Haya de La Torre (1895-1979), el fundador del APRA (Alianza Popular Revolucionaria Americana) o partido que en una época agitó banderas anti-imperialistas y de solidaridad con todos los pueblos y clases oprimidas del mundo, colocan igualmente en sus discursos a los indígenas en otro tiempo y reiteran, cuál es su caso específico, el tópico del canibalismo:

Within our borders we have everything, from the cannibal and the barbarian to the little lord living his civilized life. We are citizens with the campa and fellow countrymen of the feudal mountain lord. Once, I said that anyone wanting to travel history has only to make the trek between Lima and the eastern jungle. Given this kind of reality, what could a state be in a legal sense? (241)

La casa verde transcurre sinuosa, cual los ríos de la selva y sus meandros, entre la corroboración de estos universos ideológicos o en discrepancia con ellos, es decir, se convierte en un campo de tensiones ideológicas en el que se critican y reafirman, a la vez, realidades y visiones de mundo colonialistas.

\footnotetext{
${ }^{43}$ La actual Región Madre de Dios, donde viven los matsigenka, entre otros grupos amazónicos, fue elevada, a principios del siglo XX, a la categoría de Prefectura apostólica gracias a un acuerdo entre la Santa Sede y el gobierno peruano, y el gobierno de los grupos indígenas que allí moraban le fue encomendado a la orden de los dominicos (Huertas Castillo 30).
} 


\section{Una selva por conquistar}

En La casa verde, Vargas Llosa liga entre sí mundos usualmente separados mediante el matrimonio del cabo Lituma y la indígena aguaruna Bonifacia. ${ }^{44}$ A la manera de un etnógrafo que se adentra en una cultura extraña, el escritor informa a sus lectores de los mundos y las culturas de la selva amazónica, los cuales, valga aclarar, son desconocidos para la mayoría de los peruanos. Si consideramos la antropología como una labor de traducción, el etnógrafo emprende la difícil tarea de hacer una cultura inteligible a los ojos de otra y por ello me interesa explorar aquí qué tipo de inteligibilidad presenta el escritor sobre la selva al Perú y al mundo.

Según Historia secreta de una novela (1971), la selva amazónica es el Perú de la "Edad de piedra" que se le reveló a Vargas Llosa cuando éste conoció en un corto viaje al alto Marañón, una zona habitada por aguarunas y huambisas donde queda Santa María de Nieva, una pequeña localidad que pertenece a la Región Amazonas y donde se desarrolla parte de la novela. El viaje fue organizado en 1958 para el antropólogo mexicano Juan Comas por la Universidad de San Marcos y el Instituto Lingüístico de Verano. Este último, cuyo trabajo linguiístico se ha orientado, desde su fundación, a promover el proselitismo religioso entre los indígenas, ha sido objeto de severas críticas por una labor que muchos consideran de destrucción cultural (24-25). En Santa María de Nieva, Vargas Llosa se enteró de la explotación y opresión que sufrían los indígenas a manos de religiosos, comerciantes y caucheros, como el caso de las niñas aguarunas raptadas por monjas españolas para ser "civilizadas" y cristianizadas o el de Jum, un jefe aguaruna torturado por las autoridades por fundar una cooperativa con su gente con el fin de obtener mejores precios por el caucho que recogían.

Estos episodios y personajes fueron incluidos luego en la novela que Vargas Llosa forjó, además, con la paciente lectura de toda clase de libros sobre la Amazonia que llevó a cabo durante un año en bibliotecas y librerías de París, ya que le era casi imposible reconstruir la selva a partir de un viaje que le había dejado solamente "unos cuantos hechos, ciertas situaciones, algunos rostros y un puñado de anécdotas" (61). Es evidente

\footnotetext{
${ }^{44}$ De acuerdo al Atlas Etnolingüístico del Perú de 1988, los aguaruna pertenecen a la familia lingüística jíbaro. En 1985, su población se calculaba en 25.000 personas que habitaban en los departamentos de Amazonas, Loreto y San Martín (49).
} 
que el novel "etnógrafo" no había ejercido una larga e intensa convivencia con las culturas selváticas, el llamado trabajo de campo que fue inaugurado en la segunda década del siglo XX por Bronislaw Malinowski como piedra angular del oficio etnológico según explica Mercedes López - Baralt (54). Braulio Muñoz, quien describe a Vargas Llosa como un turista en su propio país, plantea que su limitado conocimiento de la realidad peruana ha influido en la reproducción que en sus obras hace de clichés y estereotipos injustos respecto de los habitantes nativos de la Sierra y la Selva (46). En este caso, además del desconocimiento, hay que enfatizar ante todo en la adhesión del escritor a los imaginarios de las clases dominantes sobre los indígenas peruanos.

En La casa verde, la selva es presentada como una frontera en expansión, movilizada en este caso por la explotación del caucho durante la Segunda Guerra Mundial. Las fronteras o periferias son representadas por los centros de poder como lugares de desorden y violencia continuos, lo cual legitima su intervención en ellas para producir, en palabras de Margarita Serje, una devastadora riqueza que subordina gentes y arranca recursos: "Los márgenes de la civilización son su condición de posibilidad" (9-10).. Ya que toda América Latina se constituyó a manera de una frontera desde la conquista europea, no es de extrañar que la novela reitere, a partir de las historias de dos aguarunas, el jefe Jum y la joven Bonifacia (probablemente su hija), procesos fundamentales de la historia indígena en el ámbito latinoamericano como conquista, evangelización, resistencia y asimilación, todos los cuales examinaré centrándome en la historia de la muchacha.

La casa verde, en la que se evocan igualmente textos fundacionales de la literatura, la historia y la cultura latinoamericanas, como las cartas y diarios de Colón, tiene el mérito de desarrollar personajes indígenas y darles voz creando para ellos un lenguaje que, desde la perspectiva de Cornejo Polar en El indigenismo y las literaturas heterogéneas, considero que logra la asimilación de ciertas formas propias del referente (21), en este caso el español regional hablado por los indios.

La casa verde ejemplifica de manera admirable la situación de la frontera al mostrar de modo explícitamente crítico la relación de la sociedad nacional con los grupos indígenas de la Amazonia, la brutalidad con que son tratados y la explotación a la que son sometidos por parte de los agentes que constituyen las avanzadas del poder central en la selva: autoridades políticas y militares, comerciantes, colonos y religiosos. Además, 
cuestiona la eficacia de la integración de los indígenas a una sociedad y una cultura racistas que se niegan a aceptarlos y que los ubican en los estratos más bajos y marginales de la pirámide social. Sin embargo, la visión crítica de la obra y sus aspectos novedosos son minados desde el interior mismo del texto por las descripciones del narrador omnisciente sobre los nativos, en las que se reiteran los paradigmas de civilización y barbarie al presentarlos como seres inferiores y salvajes, similares a animales.

La novela arranca con un episodio de enorme violencia en el que se narra el secuestro de unas niñas aguarunas mediante el uso combinado de regalos de baratijas y fuerza bruta para llevarlas a un internado con el fin de evangelizarlas y "civilizarlas." Dos monjas, el sargento Lituma y tres de sus hombres, armados con fusiles, llegan a un poblado aguaruna con el fin de reclutar a las niñas y se encuentran con que la población ha huido atemorizada ante la llegada de los blancos. Al poco rato, una canoa de desprevenidos aguarunas, que estaban de viaje, desembarca en el poblado - una anciana, dos hombres, dos jovencitas y un niño-convirtiéndose instantáneamente en el blanco de monjas y soldados.

El narrador omnisciente describe a estos indígenas cómo físicamente repulsivos y califica sus lenguas de inferiores, toscas y salvajes, apelando para ello a imágenes previamente consagradas en La vorágine (1924), la novela fundacional sobre el llano y la selva en la literatura latinoamericana. Así, la descripción de la anciana aguaruna como "vieja melenuda" y de sus senos "dos tubos de carne blanda y oscura penden hasta su cintura" (12) reproduce la descripción de una indígena sikuani en la famosa novela de José Eustasio Rivera. ${ }^{45}$ Los hombres son descritos como seres "sin edad, ventrudos, de piernas esqueléticas" y el niño similar a una araña y tostado cual una hormiga (13-14). Cuando la monja se acerca para tranquilizar a los aterrorizados aguaruna, hablándoles en su propia lengua, la referencia a ésta no puede ser más despectiva; "Y la Madre Angélica da un gruñido, escupe, lanza un chorro de sonidos crujientes, toscos y silbantes..." (12-14). Vargas Llosa califica aquí la lengua de los aguarunas como inferior y hará lo mismo con el quechua en Lituma en los Andes.

\footnotetext{
${ }^{45}$ En La vorágine se describen a dos mujeres sikuani de edad de la siguiente manera: "seniles, repugnantes, batiendo al caminar los flácidos senos, que les pendían como estropajos" (201).
} 
Las monjas les ofrecen a los aguarunas adultos baratijas como espejitos, collares y cuentas de colores, tal cual hizo Colón con los tainos en el Caribe, con el fin de intercambiarlas por las niñas. ${ }^{46}$ Cuando los indígenas comprenden la transacción que está en juego y se desprenden de los regalos, los soldados los encañonan y raptan a las jovencitas en una escena tensa y dramática. Aunque este episodio contiene un potencial crítico, puesto que devela el reiterado uso de prácticas coloniales hacia los indígenas en estas regiones de frontera, la representación que de ellos hace, como seres inferiores y salvajes, no hace sino repetir el discurso que sustenta tales prácticas. En este sentido, la novela se ajusta a los conceptos de civilización y barbarie presentados por el mismo Vargas Llosa en Historia secreta de una novela, en donde se expresa despectivamente de las culturas indígenas. ${ }^{47}$

El siguiente episodio de la novela narra la rebelión acaudillada por Bonifacia, una joven aguaruna que ha sido criada en el internado de las monjas en Santa María de Nieva, y quien ayuda a escapar a las nuevas cautivas traídas por el sargento y las monjas y, junto con ellas, al resto de las pupilas. Bonifacia posee unos ojos verdes como la selva y, de alguna manera, es una encarnación de la misma, de su poder y resistencia. El episodio le da voz a esta indígena y resulta plausible que la muchacha hable español ya que le ha sido enseñado, junto con la religión cristiana y la cultura de los "civilizados", durante sus varios años de reclusión en el internado al que fue llevada cuando era una niña.

Bonifacia, ante la consternación de las monjas, asume con orgullo su acto, enfatizando que no ha sido un descuido sino una decisión de su parte, conmovida ante las nuevas cautivas que solicitaron su ayuda. Les revela, además, que ella ha continuado hablando "pagano," es decir, su propia lengua, ya que no la olvidó al seguirla escuchando en boca de las niñas que engrosaban las filas del internado. Esta validación de una lengua indígena pone por supuesto en entredicho uno de los pilares fundamentales de la nación peruana forjada por las elites, cual es la lengua española, así en el país se hable

\footnotetext{
${ }^{46}$ En sus apuntes del 11 de octubre de 1492, Colón relata: "les di a algunos de ellos [los indios] unos bonetes colorados y unas cuentas de vidrio que se ponían al pescuezo, y otras cosas muchas de poco valor, con que hobieron mucho placer y quedaron tanto nuestros que era maravilla" (30).

${ }^{47}$ Así cuando habla en Historia secreta de una novela de la posibilidad de que las pupilas de las monjas regresen a sus comunidades: "Ellas difícilmente podrían adaptarse a vivir como antes, semi-desnudas, adorando serpientes o árboles, a ser una de las dos o tres mujeres-esclavas de un cacique" (29). Esta descripción resulta por lo demás rudimentaria y de una enorme pobreza.
} 
extensamente el quechua, también el aimara, y en la Amazonia exista una enorme diversidad de lenguas.

Las religiosas, apelando a la historia personal de Bonifacia, quien resultó muy difícil de "civilizar," interpretan el episodio de la fuga de las internas como una vuelta a la indecencia, el pecado y el salvajismo (40). Le recuerdan a la muchacha los malos instintos que la animaban cuando ella llegó a la misión desnuda (38) y recalcan que "era como un animalito" y que ellas le habían dado hogar, familia, nombre y Dios (39). Este corto sermón justifica plenamente la misión civilizadora de las madres al presentar a las niñas como seres sin ningún lazo social, por consiguiente sin cultura y, peor aún, sin Dios, a la par que tiende un velo sobre la violencia de la que han sido víctimas al ser separadas por la fuerza de sus familias y comunidades. Bonifacia, con su rebelión, ha revertido por completo este proyecto civilizador y la novela muestra entonces la posibilidad de que los indígenas puedan resistirse a los proyectos que buscan exterminarlos culturalmente con el fin de asimilarlos e integrarlos a la nación; de hecho, después de que soldados y autoridades se movilizan en busca de las fugitivas no logran capturar de nuevo a las dos aguarunas recientemente raptadas.

El lector no puede por menos que contrastar los discursos de las monjas sobre el bien que les hacen a sus pupilas con el violento episodio del rapto de las niñas aguarunas con el que se inicia la novela, lo cual le permite confrontar los paradigmas de civilización y barbarie y preguntarse quiénes son realmente los salvajes en este caso. Sin embargo, en este nuevo episodio, los indígenas y sus lenguas se asocian de nuevo con lo "primitivo" y lo "salvaje." Bonifacia, por ejemplo, es descrita como poseedora de una expresión "entre huraña e indolente", sus pies semejan "dos animales chatos, policéfalos" (23) y su lengua, gruñidos de animal (41). Así, aunque la novela critica los métodos violentos empleados por las monjas y las autoridades peruanas, los indígenas siguen siendo confinados en ella en el estadio del salvajismo sin que en la obra se desarrolle una actitud de respeto y comprensión hacia sus culturas.

En castigo por su rebelión, Bonifacia es expulsada del internado y queda como un barco a la deriva puesto que no tiene un lugar al que pueda llamar suyo y tampoco una comunidad y una familia a la que pueda regresar porque ya no sabe quiénes la conformaban ni dónde están. El práctico Nieves, o sea el guía de la región, y su mujer la

Poligramas 36, segundo semestre 2011, ISSN 0120-4130. 
recogen y se la llevan a su casa. Le presentan al sargento Lituma con quien la muchacha acaba contrayendo matrimonio para viajar luego a la ciudad costanera de Piura, dejando atrás la selva.

Una vez en Piura, Bonifacia se ve sujeta a todas las dificultades que trae consigo para los indígenas el proceso de integración a una sociedad racista que se niega a aceptarlos y que los discrimina continuamente. Lituma deja de ser afectuoso con ella y empieza a maltratarla y a despreciarla porque la muchacha no se adapta a la ciudad. El grupo de amigos más cercanos del sargento, los llamados inconquistables, la consideran una especie de animalito porque no entiende nada sobre este nuevo medio ambiente y pregunta por todo e intentan además seducirla (223). La "peruanidad" se vuelve un bien inalcanzable para la muchacha, atropellada por la ignorancia, el etnocentrismo y el machismo de Lituma y sus amigos. Algo de su fuerza y de su antigua rebeldía subsisten sin embargo todavía en ella cuando afirma que jamás sentirá vergüenza de su tierra, algo que se supone debería sentir para poderse integrar al mundo de la costa que encarna la nación (290).

Hacia el final de la novela, cuando Lituma es encarcelado por haber dado muerte a un hombre en una pelea, Bonifacia, carente de medios de subsistencia, se hace amante de Josefino, un amigo del sargento, y comienza a trabajar de prostituta en La casa verde, el prostíbulo que da el nombre a la novela, en donde la llaman la Selvática. Gracias a una conversación sostenida entre ella y Don Anselmo, el afamado arpista dueño de la primera y legendaria Casa Verde, nos enteramos de que el hombre es oriundo de la Selva, y que su prostíbulo no es verde por azar ya que significa el entronque entre ésta y la Costa, el fin del aislamiento entre estas dos regiones. Al final de la obra, el ánimo de resistencia de Bonifacia termina quebrantado al término de su ciclo de asimilación y, en consecuencia, opta por negar la realidad de su origen, pretende ignorar su lengua y se refiere a la selva como un lugar donde hay bastantes blancos y donde los chunchos - término despectivo para nombrar a los indios de aquella - casi ni se ven. El ingreso a la nación le ha exigido a la muchacha un total despojo de sí misma, incluido su propio cuerpo, y es evidente que este proyecto de nación centrado en un prostíbulo no deja de resultar altamente irónico. El destino de Bonifacia, signado en parte por la rebelión y el desafío, culmina un ciclo que ya se preveía en los primeros capítulos de la novela y que Vargas Llosa mismo señala

Poligramas 36, segundo semestre 2011, ISSN 0120-4130. 
en Historia secreta de una novela cuando escribe que las niñas indígenas criadas en las misiones terminaban de sirvientas y prostitutas.

En La casa verde no existe un camino de negociación para los indígenas con las nuevas realidades que enfrentan y el costo que pagan por la asimilación es la degradación social y la pérdida de sus historias, culturas y lenguas. Si bien este proceso es presentado aún de manera crítica en esta novela, así se enfatice en el salvajismo y primitivismo de los indígenas, Vargas Llosa se apartará finalmente de todo cuestionamiento en El hablador al plantear la extinción cultural de los mismos como una necesidad ineludible para alcanzar el desarrollo y la modernización del Perú.

\section{De selvas prístinas}

El hablador se publicó en 1987, es decir, 20 años después de La Casa Verde, cuando tanto la selva como la sociedad peruana y el mismo Vargas Llosa habían experimentado notables transformaciones. Hacia finales de los años ochenta, la selva que Vargas Llosa había conocido en 1958 ya había sido conectada al resto del país mediante la Carretera Marginal de la Selva, continuaba recibiendo emigrantes serranos que disputaban sus territorios a los nativos y había sido sometida a la modernización del narcotráfico y a los planes económicos de los inversionistas extranjeros. El escritor, por su parte, había dejado de ser un intelectual de izquierda para convertirse en un ardiente defensor del neoliberalismo.

El hablador está estructurado con base en dos narradores que manejan dos registros literarios distintos, intercalados a lo largo del texto. Uno es un escritor limeño, antiguo estudiante de la Facultad de Letras de la Universidad de San Marcos en la década de los cincuenta, quien nos narra la historia de su amigo Saúl Zuratas, un estudiante de etnología de origen judío, apodado Mascarita por causa del enorme lunar morado que cubría su cara. El otro es un hablador o contador de historias matsigenka, quien estructura su relato a manera de una reelaboración literaria de los mitos e historias de la tradición oral de este grupo arahuaco de la selva peruana. Ambos relatos transcurren de manera paralela y supuestamente independiente y sólo hacia el final de la novela descubrimos que el etnólogo es el hablador y que la obra es la historia de su conversión en matsigenka. En realidad, no hay una voz indígena, una de las características que más alabó la crítica

Poligramas 36, segundo semestre 2011, ISSN 0120-4130. 
en la recepción inicial de la novela, y lo que tenemos es la voz del escritor limeño en el proceso de escribir sobre un hablador en su labor de contar historias, como explica Jean O'Bryan-Knight: "Instead of having a single narrator for two parallel narrative situations, we have two narrators on different diegetic levels, the second of which is the creation of the first" (78) [En vez de tener un solo narrador para dos situaciones narrativas paralelas, tenemos dos narradores en distintos niveles diegéticos, uno de los cuales es la creación del primero (mi traducción)].

A diferencia de La casa verde, la asimilación de los indígenas deja de ser presentada como un proyecto brutal y sin sentido en El hablador y se propugna, al contrario, por su desaparición cultural para que el Perú pueda entrar plenamente en el camino de la modernización en un nuevo orden mundial globalizado. Los matsigenka ya no caben en el orden neoliberal y la conversión de Rául Zuratas (Mascarita) en hablador matsigenka es vista como una salida quijotesca sin razón de ser en el mundo moderno que se puede interpretar como una alegoría del sin sentido de la existencia de los grupos selváticos en el mundo actual.

En los capítulos III, V y VII, dedicados al hablador - figura que por cierto no existe entre los matsigenka- y sus relatos, se nos presentan una selva y unos indígenas casi prístinos, por fuera del tiempo y de la historia, aislados y marginales dentro de la nación peruana, envueltos en el aura de la nostalgia que suscita lo que se da por perdido. En esta selva se desenvuelve la historia del hablador, un individuo aislado y solitario, también, cuyo grupo es presentado como minúsculo, fragmentado y vulnerable: "Las fotos mostraban con elocuencia cuan pocos eran...su aislamiento, su arcaísmo, su indefensión" (9). Los matsigenka son despojados dentro de la novela de contemporaneidad y ubicados en la prehistoria, un tiempo obviamente distinto al del narrador-escritor occidental, situación que contribuye a alejarnos a su vez como lectores de ellos. Al distanciar los capítulos dedicados al hablador de la contemporaneidad, la tradición oral y la cultura de los matsigenka pierden vida y fuerza y terminan asumiendo el carácter petrificado de piezas de museo.

Desde la primera página, Vargas Llosa introduce una imagen de los indígenas hecha de lugares comunes, estereotipos y clichés que se fijan en el texto para no salir ya nunca de él, imágenes que adquieren fuerza mediante una estrategia textual que las coloca

Poligramas 36, segundo semestre 2011, ISSN 0120-4130. 
repetitivamente a lo largo de la cadena sintagmática. Esta repetición no sólo las refuerza entre sí, sino que corrobora y reivindica a la vez un imaginario colectivo que ha reafirmado por siglos la discriminación contra los "salvajes" que habitan la selva. El primer párrafo de la novela presenta a los matsigenka como unos seres débiles y exóticos, asimilables a plantas:

Los anchos ríos, los corpulentos árboles, las frágiles canoas, las endebles cabañas sobre pilotes y los almácigos de hombres y mujeres, semi-desnudos y pintarrajeados, contemplándome fijamente desde sus cartulinas brillantes (7). Descritos como almácigos, los matsigenka son asimilados al mundo vegetal, ${ }^{48}$ de ahí se sigue al despectivo término de pintarrajeados y de éste al de semidesnudos, es decir, se refuerzan así los lugares comunes de un imaginario negativo sobre los indígenas que sin embargo continúa dotado de una gran fuerza de inercia y se usa casi que inconscientemente. ${ }^{49}$ La selva prístina donde moran los matsigenka se encuentra amenazada, no obstante, por empresas económicas de diversa índole, entre ellas las madereras y petroleras, que condenarán a aquellos, en un futuro no muy lejano, a una extinción que la novela plantea como ineludible:

Si el precio del desarrollo y la industrialización, para los dieciséis millones de peruanos, era que esos pocos millares de calatos tuvieran que cortarse el pelo, lavarse los tatuajes y volverse mestizos -o, para usar la más odiada palabra del etnólogo: aculturarse-, pues, qué remedio. $(24)^{50}$

\section{Una transculturación marginal}

El contrapunteo entre los dos narradores, el escritor, portavoz de Occidente que propugna por la extinción cultural de los matisgenka, y el etnólogo, quien, por el contrario, defiende el derecho de estos indígenas a su cultura y territorios, constituye el eje vertebral de la novela que parece resistir el impacto modernizador en la selva al apelar, creativamente, a elementos de la cultura que sufre el choque, en este caso la tradición oral

\footnotetext{
${ }^{48}$ Los almácigos son semilleros donde se crían las plantas que luego han de trasplantarse y son también árboles de la isla de Cuba.

${ }^{49}$ La semi-desnudez de los indígenas siempre ha sido considerada un gran problema y una de las tareas inmediatas que asumen los blancos que entran en contacto con ellos es vestirlos. Pero los matsigenka, tanto hombres como mujeres, usan una cusma de algodón que los cubre hasta los pies, detalle que se pasa por alto en El hablador y denota hasta qué punto tienen fuerza los estereotipos prevalecientes en la cultura peruana con respecto a los indígenas.

${ }^{50}$ Beatriz Huertas Castillo documenta la frenética extracción de madera de caoba en lo que hoy es la Región Madre de Dios, en territorios de pueblos indígenas, así como la prospección de fuentes de petróleo (66-78).
} 
matsigenka. ${ }^{51}$ La labor de Mascarita, quien se ha asimilado a la cultura matsigenka, recuerda la del grupo de intelectuales y escritores latinoamericanos, a quienes Rama llama los transculturadores, los cuales, bajo el impacto modernizador de la década de los treinta, actuaron como intermediarios a fin de negociar el efecto de este impacto en las culturas regionales cuyos valores tradicionales estaban siendo agredidos (68).

Sin embargo, el proceso de transculturación que se desarrolla en la novela, el cual podría cuestionar seriamente los paradigmas de civilización y barbarie y abrir amplios espacios de comunicación con las culturas indígenas, pierde toda fuerza en la obra puesto que Raúl Zuratas (Mascarita) permanece en ella como una figura aislada, solitaria y marginal, casi carente de importancia intelectual, al contrario de lo que sucede con los transculturadores analizados por Rama y a quienes el crítico les concede una importancia capital dentro de la cultura latinoamericana. En efecto, el etnólogo es configurado en la obra como un personaje doblemente marginal en su condición de manchado y judío, marginalidad que es precisamente la que lo conecta con los indígenas siendo ambos representados como un estigma y un estorbo para la nación:

Ambos Mascarita y los matsigenka eran una anomalía para el resto de los peruanos; su lunar provocaba en ellos, en nosotros, un sentimiento parecido al que en el fondo alentábamos por esos seres que vivían, allá lejos semidesnudos, comiéndose los piojos y hablando dialectos incomprensibles. (30) ${ }^{52}$

De modo deliberado, el narrador-escritor desvaloriza la actividad transculturadora de Mascarita, es decir, su negociación con la cultura matsigenka, y rechaza asumir el mismo la función de mediador entre el impacto modernizador y la cultura local, distanciándose de manera crítica de la figura del estudiante de etnología, cuya historia elabora literariamente, llevando a cabo una labor de zapa permanente contra sus ideas en defensa de los matsigenka.

\footnotetext{
${ }^{51}$ El misionero dominico Andrés Ferrero presenta una breve reseña de la vida de los matsigenka en su libro Los Machiguenga. Desde tiempos coloniales, los matsigenka tuvieron contacto con expedicionarios españoles y misioneros jesuitas, agustinos y dominicos. Desde mediados del siglo XIX, los cascarilleros o recolectores de quinina, primero, y los caucheros, después, comenzaron a incursionar en el territorio de los matsigenka para esclavizarlos y explotarlos como mano de obra gracias a la impunidad de ley "calibre 44". En los inicios del siglo XIX, la actual Región Madre de Dios fue declarado Prefectura Apostólica y entregado a la orden de los dominicos. En 1902, los religiosos fundaron la misión matsigenka de Santo Domingo de Chirumbia, la cual terminó constituyéndose en una amenaza para los caucheros que dependían de la mano de obra matsigenka para explotar el caucho (42-48).

${ }_{52}$ Para un análisis detallado de la mancha y sus conexiones con la sociedad colonial, en la cual se hablaba de la mancha de color vario para el caso de los mestizos, véase mi artículo "Un mancha en la faz de la nación: la representación de los indígenas en El hablador de Mario Vargas Llosa" (2005).
} 
Mientras que Rama le concede una gran importancia a los valores tradicionales de las culturas regionales que les permiten resistir y negociar creativamente los impactos modernizadores, el narrador-escritor las presenta continuamente como arcaicas, indefensas, débiles y marginales apelando de nuevo al esquema evolucionista. A su juicio, ellas constituyen la barbarie que el Perú debe eliminar imponiendo a tal fin la supremacía de la Costa civilizada. Ahora bien, ¿para qué crear una obra cuya validez es socavada, por así decirlo, desde su interior mismo? ¿Para qué reelaborar literariamente la tradición oral de los matsigenka plasmándola en una obra que ha circulado por Perú y el mundo? ¿Para qué ocuparse de una cultura local que se considera debe ser asimilada para convertir al Perú en una nación homogénea? El sentido último de la obra es lo que se podría llamar una actitud museográfica en la medida que comparte el afán que guiaba a la llamada antropología de rescate a documentar apresuradamente la cultura de grupos al borde de la extinción y coleccionar objetos producidos por los mismos como testimonio último de su existencia.

De hecho, en la obra se lamenta con tristeza la pérdida de la cultura de los matsigenka a la par que se promueve su irremediable asimilación, según explica Misha Kokotovic, Renato Rosaldo ha acuñado el término de "nostalgia imperialista" para describir ese anhelo que los modernos sienten por las culturas desaparecidas y vencidas y cuya destrucción se consideraba una consecuencia irremediable e inevitable de la modernización. (1) La obra crea así una fisura irremediable entre las regiones y culturas en el Perú al negar toda posibilidad de que los indígenas selváticos -representados por los matsigenka-intervengan en la nación como un potencial cultural valioso e importante, con derecho a resolver su propio destino. Esta fisura se hace extensiva al campesinado quechua de la Sierra en Lituma en los Andes, donde aparece descrito como preso de un barbarismo atávico que sólo causa violencia y destrucción en Perú. En dicha novela, esta Sierra inmutable y por fuera de la historia se contrapone a una selva que, a diferencia de la de El hablador, ya no es marginal a la nación sino que posee, por el contrario, una gran importancia económica gracias al tráfico de drogas que la ha insertado en la economía global ilegal. 


\section{Una selva "narcotizada"}

Lituma en los Andes nos presenta una selva "neoliberal," conquistada y modernizada por la economía del narcotráfico y su violencia. ${ }^{53}$ Parte de la acción de la novela se desarrolla en Tingo María, población ubicada en el Valle de Huallaga, en donde en la década de los ochentas se cultivaba un $40 \%$ de la producción total de coca en el mundo (Kawell 426). ${ }^{54}$ La novela nos coloca ante una selva dinámica que bulle de vida con gentes y culturas de las más variadas procedencias, de dinero, de actividad y violencia. En Lituma, la Selva ya no es marginal a la nación ni aparece situada en otro tiempo; está, por el contrario, inmersa en la vorágine de las economías ilegales actuales y reviste una importancia fundamental para las mismas. Esa vorágine envuelve asimismo a los personajes de la novela, quienes se ven compelidos a desplazarse por toda la geografía del Perú, dejando así retazos de su historia en distintos lugares y actuando como vasos comunicantes que enlazan diferentes fenómenos políticos y culturales de la realidad nacional.

En la novela, esta nueva época de la selva aparece encarnada en la pareja conformada por el guardia serrano Tomás Carreño y la prostituta costeña Mercedes, quienes se conocieron en Tingo María cuando aquel trabajaba como guardia personal de un narcotraficante cuya amante era Mercedes. El sargento Lituma, quien aparece por primera vez en La Casa Verde raptando a la fuerza niñas aguarunas para llevarlas al internado de las monjas, reaparece luego en la Sierra como protagonista de Lituma en Los Andes. Allí, gracias a las historias de su asistente el guardia Carreño, entra en contacto con una selva incorporada al narcotráfico. Mercedes, la amante del narcotraficante apodado el Chancho, de la cual se enamora el joven guardia es, al igual que Lituma, oriunda de Piura, pero los avatares de la vida la lanzaron primero a Lima, luego a Tingo

\footnotetext{
${ }^{53}$ Desde los años setenta, la selva se ha ido convirtiendo en un inmenso laboratorio de producción de cocaína, tanto en Perú como en Colombia. Los colonos, ante el fracaso de sus proyectos agrícolas, aceptan involucrarse en un cultivo que es mucho más rentable para ellos y se adapta a las condiciones de la selva, ya que ha sido practicado allí desde tiempos muy antiguos. Partes de la selva donde se cultiva coca se han convertido también en focos de la actividad guerrillera insurgente: en el caso de Colombia las FARC y en el de Perú el selvático valle de Huallaga estuvo bajo el control de Sendero Luminoso y el MRT (Kawell 425-429). Al igual que sucedió en el pasado con la quina y el caucho, la coca ha logrado insertar también a la selva en un mercado mundial si bien es preciso aclarar que su cultivo no hace parte de un ciclo de economía netamente extractiva.

54 Jo Ann Kawell explica que el valle del Huallaga parece ser el lugar donde se domesticó originalmente la coca: Some ethnobotanists maintain that the Huallaga Valley is the place where coca was first domesticated some eight to ten thousand years ago. There is clear archeological evidence that coca has been an important economic resource for the valley dwellers since long before the Inca empire. In pre-Inca and Inca times, during Spanish rule, and into the Republican era, coca has been a key crop in trade and tribute, especially in the highlands. (430)
} 
María y hacia el final de la novela a la Sierra, adonde va en busca de Carreño. Al verla, Lituma se da cuenta que la muchacha es una prostituta que él había conocido en Piura. La novela ejemplifica así el hecho de que el narcotráfico, como fenómeno social y económico, ha logrado romper el aislamiento tradicional entre las distintas regiones del Perú. Sin embargo, nos corresponde a nosotros, como lectores, reconstruir este rompecabezas de personajes e historias que saltan de un texto a otro y desentrañar sus significados e importancia en términos de la nación como comunidad imaginada.

\section{De idolatrías renovadas}

En Lituma en los Andes, la Sierra figura como una variante del discurso evolucionista que hemos visto en La casa verde y en El hablador. No es posible, sin embargo, mirar la Sierra como un territorio vacío que debe ser conquistado ni hay manera de caracterizar a esta población como totalmente primitiva y ubicada en la Edad de Piedra, pero sí se la considera una población atrasada con tintes primitivos que nunca ha logrado alcanzar la civilización y que además, en términos culturales, no ha sido "conquistada" del todo ya que persiste en el uso de una lengua y unas creencias extrañas y ajenas al mundo "civilizado" de la costa. La novela se constituye así en una réplica continuada del discurso de las elites criollas que responsabiliza permanentemente al campesinado quechua de las desgracias del Perú. Para gran parte de las elites, el país estaba atrapado en el problema insalvable del indio serrano; insalvable en la medida que parecía casi imposible occidentalizarlo y encaminarlo por la vía del progreso.

En Lituma en los Andes, su protagonista, el sargento Lituma, llega a un poblado de la Sierra para esclarecer el misterio de tres asesinatos. Esta misión lo enfrenta, por primera vez en su vida, al complejo mundo cultural andino en el que dominan una lengua y unas creencias que él tiende a rechazar y despreciar pero que a la par lo desconciertan. Lituma expresa reiteradamente en la novela los estereotipos con los que se suele estigmatizar a los campesinos quechuas, y es interesante que Vargas Llosa se haya valido de un personaje que evidentemente no pertenece a la élite para mostrar que las clases dominantes parecían haber logrado imponer su visión del indio de la Sierra como parte de su hegemonía cultural sobre buena parte de la población peruana.

Poligramas 36, segundo semestre 2011, ISSN 0120-4130. 
El costeño pone constantemente de presente la imposibilidad de relacionarse con esos serranos herméticos e impenetrables con los cuales no se puede entrar en diálogo, dicho de otra manera, de construir la nación. La novela releva la diferencia lingüística como uno de los elementos que delimita significativamente la división entre la Sierra y la costa y actúa a manera de una marca de alteridad. Así, en la primera página de la obra, el sargento Lituma se refiere al quechua despectivamente, tal como lo hace el narrador omnisciente de La casa verde al aludir a la lengua aguaruna: "La india repitió esos sonidos indiferenciables que a Lituma le hacían el efecto de una música bárbara. Se sintió de pronto muy nervioso" (11). Los serranos, a su vez, tienen dificultades con el español de la Costa: "No todos entendían el español costeño apocopado y veloz del oficial" (85). A la barrera lingüística se suma la valoración diferencial del quechua y el español, la cual constituye el fenómeno de la diglosia que remite, como explica Martín Lienhard:

a la coexistencia, en el seno de una formación social, de dos normas lingüísticas de prestigio social desigual. Una de ellas, la norma alta, es la usada por los sectores sociales dominantes y es un idioma de tradición escrita, en este caso el español. La otra, la norma baja, corresponde a los sectores populares o marginados y es una lengua de tradición oral. (72)

Si la obra de José María Arguedas representa el titánico esfuerzo de mediar entre estas barreras lingüísticas y culturales, este no es el caso de Vargas Llosa. Aparte de unas pocas palabras en quechua que salpican la novela, el narrador en tercera persona es totalmente impermeable a la existencia de la norma lingüística considerada como inferior. Esta primera diferencia se une a otra, la cultural, es decir, las creencias propias de los serranos que Lituma considera un sartal de embustes, "cosas que no se cree ya nadie en un lugar civilizado" (105) y que comenta de una manera tal que termina delineando el panorama sombrío de unos hombres quienes supuestamente viven amedrentados por las fuerzas sobrenaturales que pueblan los cerros o por los pishtacos que chupan la grasa y la sangre de los seres humanos. Este tipo de descripción corresponde claramente a lo que una antropología evolucionista rotulaba de primitivo, seres débiles frente a las fuerzas de la naturaleza que tenían que acudir a la magia y la superstición en un intento de controlarlas. Incluso el paisaje es descrito igualmente en términos sombríos por Lituma, 
quien siente "la presencia aplastante y opresiva de las montañas macizas, del cielo profundo de la sierra" (103).

A medida que Lituma avanza en la investigación de los asesinatos, la imagen de los serranos se torna cada vez más negativa. En efecto, éste va descubriendo que, bajo su aparente cristianismo, los campesinos de la región siguen conservando rituales antiquísimos y que fueron ellos quienes mataron a las tres personas para ofrecerlas como sacrificios humanos a sus dioses tutelares, los apus, y así evitar desgracias en la carretera que los pudieran dejar sin trabajo. Y no solamente los han ofrendado a sus dioses sino que, además, los han consumido en sus "bárbaros ritos." Los campesinos de la región manejan, entonces, un doble código cultural que Martín Lienhard analiza en términos de normas altas y bajas aplicando para ello el concepto de diglosia a la realidad social. Si bien éstos han asumido el cristianismo oficial que les ha sido impuesto como la norma alta, siguen utilizando sus creencias tradicionales como una norma baja que practican en relativa clandestinidad y, según sea el caso, eligen la norma que consideran más adecuada (74-76). El sargento Lituma apunta a esta situación cuando comenta el asunto de los tres sacrificados:

¿Cómo era posible que estos peones, muchos de ellos acriollados, que habían terminado la escuela primaria por lo menos, que habían conocido las ciudades, que oían radio, que iban al cine, que se vestían como cristianos, hicieran cosas de salvajes calatos y caníbales?"(205)

Lituma vincula aquí a los serranos con los selváticos y se lamenta de su abominable conducta. Es claro que no está interpretando la situación en el sentido de diglosia sino como efecto de un cristianismo superficial practicado por falsos creyentes, es decir, en términos de idolatría y herejía. Estos términos derogatorios no permiten entender que el uso de una u otra norma cultural revela, por el contrario, una gran riqueza y la posibilidad de tomar decisiones de acuerdo a las conveniencias de los actores sociales. Por eso, la ofrenda humana no pasa de ser presentada en el libro como un acto de salvajismo ejecutado por seres intemporales, ya que reproduce comportamientos de los más remotos tiempos. En este caso se trata de los sacrificios que los huancas-un grupo preincaico que habitaba el centro del Perú-practicaban antes de la Conquista, según le explica a Lituma un profesor de arqueología. El sargento utiliza esta información para descifrar el 
misterio de los asesinatos al relacionar, de manera inmediata y sin mediación, este vetusto pasado con el presente, como si las sociedades y culturas de la Sierra fueran inmunes al paso del tiempo.

Sin embargo, Lituma no logra permanecer ajeno al medio que lo rodea. De alguna manera, comienza a dudar si tales creencias son ciertas o no y termina aceptando algunas de las que tanto ha rechazado: “¿Seria cierto que la bruja de Doña Adriana había matado a un pishtaco?" (67) Y cuando sale vivo de la avalancha o huayco da las gracias como lo hubiera hecho un serrano: "Gracias por salvarme la vida, mamay, apu, pachamama o quien chucha seas" (209). Pero su permeabilidad es insignificante en el contexto de una novela que adolece de la creación de personajes transculturadores que puedan mediar entre los dos mundos antagónicos de la costa y la Sierra.

Los dos mediadores que aparecen en la novela, el cantinero Dionisio y su mujer Adriana, quienes fueron los que impulsaron a los peones serranos a realizar los sacrificios rituales, vinculan entre sí a la Sierra con la selva y representan la idea muy extendida del poder que esta última tiene en términos de chamanismo, curación y brujería. ${ }^{55}$ Doña Adriana es una bruja capaz de adivinar el futuro en las cartas astrológicas, los naipes y las hojas de coca, es decir maneja diversos repertorios culturales, tanto así que "se contaba que venía de la región de Parscambamba, una región entre serrana y selvática” (38). De Dionisio se decía que "había sido criado por una comunidad de idólatras en las alturas de Huanta y que había vivido en la selva, entre chunchos caníbales" (243). Estos mediadores son revestidos, sin embargo, de un carácter negativo ya que su papel consiste en utilizar las malas artes, aprendidas posiblemente en la selva, para convencer a unos serranos idolatras de realizar unos actos bárbaros que los acaban identificando con los chunchos. Al final de la novela, Lituma saldrá para esta región en calidad de jefe del puesto del ejército en Santa María de Nieva y el único recuerdo que llevará consigo será el del acto de canibalismo, memoria que no es vana ni carece de significado ya que tanto la Sierra como la Selva se engarzan simbólicamente en sus últimas páginas mediante la imagen del

\footnotetext{
55 En su artículo "De mestizajes, heterogeneidades, hibridismos y otras quimeras," Martin Lienhard aplica el paradigma de la diglosia, proveniente de la socio-lingüística, al dominio de las prácticas culturales. "La diglosia remite a la coexistencia, en el seno de una formación social, de dos normas lingüísticas de prestigio social desigual" (72), por ejemplo, el español y el quechua. La diglosia, aplicada a la cultura, implica la existencia en la sociedad colonial de una norma oficial o alta, la de la metrópoli, y una norma baja despreciada que corresponde a los vencidos.
} 
canibalismo que ha pendido como un terrible estigma sobre los pueblos indígenas desde la Conquista y que Oswald de Andrade, el escritor modernista brasileño, logró subvertir tan brillantemente en su Manifesto antropófago (1928) al celebrar la antropofagia como una salida al problema de la identidad brasileña y como un antídoto contra el imperialismo.

La novela establece así un paralelo entre este mundo de idólatras y chunchos y las actuaciones de Sendero Luminoso en el sentido de que tanto los unos como los otros ejercen una violencia irracional - los primeros mediante sus creencias ancestrales y los segundos a través de su ideario político-, pero en ningún momento relaciona la apelación a la violencia con los profundos desequilibrios sociales y económicos que caracterizan a la sociedad peruana. Si bien es cierto que se admite que los terrucos, es decir, los senderistas castigan ciertos abusos que se cometen en la Sierra, en ninguna parte se tratan problemas tan fundamentales como la tenencia de la tierra. Los terrucos hablan quechua y muchos de ellos son indígenas y lo que la novela muestra es que se puede pasar de un bando a otro con facilidad, de un "salvajismo" de vieja data a uno de nueva. En este sentido, el final de la novela es bien desalentador porque pareciera que no hay salida alguna para un Perú amenazado por estos salvajes de viejo y nuevo cuño; ni siquiera la región costanera, postulada como el núcleo de la nación peruana, parece poseer la fuerza suficiente para cohesionar entre sí las fuerzas centrífugas de la Selva, la Sierra y Sendero Luminoso. La única historia que culmina felizmente dentro de la novela es el romance entre el guardia serrano Tomás Carreño y la prostituta costeña Mercedes. Vargas Llosa propone así una solución similar a la de los romances nacionales del siglo XIX, analizados por Doris Sommer en Foundational Fictions, al intentar reunificar un país dividido y al borde del colapso mediante la unión amorosa de los representantes de sus partes en conflicto. La relación entre la piurana blanca y el buen indio serrano aculturado se presenta, según plantea Kokotovic, como la única solución a la violencia bárbara de Sendero y los sacrificios humanos atávicos promovidos por Dionisio y Adriana. La solución parece sin embargo totalmente inadecuada para los gravísimos problemas que aquejan al Perú contemporáneo, en vez de reflexionar sobre una posible solución colectiva, la novela plantea el escape al reino del amor y la intimidad (194). 
Tomás es trasladado a la costa y al igual que Lituma le da la espalda a la Sierra y sus problemas, como ha sido la actitud tradicional de las elites peruanas.

\section{Suturar la fisura}

En las novelas que he analizado, Vargas Llosa se ha servido de una amplia gama de discursos, correspondientes a distintos períodos de la historia peruana, para proponer la nación que él desea e imagina: una nación mestiza y homogénea que no ofrezca ningún tipo de resistencia al nuevo orden neoliberal y global. Estas obras son un muy interesante ejemplo de cómo un autor puede hacer uso de un capital imaginario, acumulado a través del tiempo en contra de los indígenas para responder a las nuevas circunstancias mundiales, los viejos discursos sirven así para defender los nuevos intereses, justificando la eliminación cultural de los indígenas con el fin de acceder a los recursos existentes en sus territorios. La contraparte más notoria de Vargas Llosa sería Arguedas, quien también tenía en mente su propia idea de nación: una nación abierta y pluralista que aceptara el valor de las culturas indígenas y mestizas y las acogiera como elementos fundamentales en el conjunto del país. Mientras que Arguedas incorpora en sus obras los movimientos sociales más importantes que sacudieron el Perú hasta que él vivió, Vargas Llosa los ignora o los acoge muy superficialmente. Hay una especie de inercia en esa obra suya que no hace sino disponer de manera distinta, cual un caleidoscopio, las mismas ideas una y otra vez, lo cual sólo refleja las variantes de una clase dirigente que ha sido incapaz de gestar una nación que pueda progresar y ofrecer una mejor vida a sus habitantes.

Irónicamente, sin embargo, la modernización tan anhelada por Vargas Llosa ha traído consigo lo que el sociólogo peruano Aníbal Quijano denomina la "cholificación" del Perú. La "cholificación" constituye un proceso en el cual grandes masas de población indígena vinculada a los nuevos trabajos abiertos por los procesos de industrialización en el Perú, rechazan, al desplazarse a las grandes ciudades y los centros agrícolas, pesqueros y mineros, la asimilación total a la cultura criolla occidentalizada y la pérdida de sus culturas indígenas de origen. En un movimiento sin precedentes en la historia peruana, estos sectores de población indígena, los cuales constituyen sectores sociales y culturales intermedios emergentes, persisten, a través de las generaciones, en mantener por libre decisión los elementos de la cultura indígena que forman parte de su mundo cultural 
(7071) La "cholificación" constituye un rechazo rotundo a la asimilación e integración del indio propugnada por las elites y por Vargas Llosa como la solución a los problemas del Perú. Según Quijano, implica el surgimiento de una nueva vertiente cultural dentro de la sociedad peruana, el cholo no es por lo tanto solamente un nuevo grupo social en emergencia sino también el portador de una cultura en formación, al cual Quijano ve como uno de los más activos agente de cambio dentro de la sociedad peruana actual (73, 77). En este proceso cultural, el cholo ha logrado negociar el mundo occidental criollo y el indígena contemporáneo sin que este último desaparezca sino que por el contrario sea afirmado decididamente, adaptándolo a las nuevas realidades. Ha logrado suturar entonces la fisura irremediable y se ha salvado de la asimilación abyecta a la que es condenada Bonifacia en La casa verde, marcando su impronta sobre el conjunto del Perú, cuya sociedad tuvo que enfrentar la violencia por Sendero Luminoso y el ejército peruano, violencia atribuida absurdamente por Vargas Llosa a una supuesta barbarie atávica de los indígenas peruanos.

\section{Bibliografía}

Chirif, Alberto. "El colonialismo interno en un país colonizado: el caso de la Amazonia peruana." Saqueo Amazónico. Ed. Alberto Chirif. Iquitos, Perú: CETA, 1983. 47-80.

Colón, Cristóbal. Textos y documentos completos. Ed. Consuelo Varela. Madrid: Alianza Universidad, 1982.

Cornejo Polar, Antonio. "El indigenismo y las literaturas heterogéneas: su doble estatuto socio-cultural." Revista de Crítica Literaria Latinoamericana. 4.7-8. (1978):7-21.

Fabian, Johannes. Time and the Other. How Anthropology Makes Its Object. New York: Columbia University Press, 1983.

Fenwick, M.J. Dependency Theory and Literary Analysis: Reflections on Vargas Llosa's The Green House. Minneapolis: Minn.: Institute for the Study of Ideologies and Literatures, 1981.

Ferrero, Andrés. Los machiguengas: tribu selvática del sur-oriente peruano. Villava, España: Editorial OPE, 1967.

Flindell Klarén, Peter. Perú. Society and Nationhood in the Andes. New York: Oxford University Press, 2000. 
Flores Galindo, Alberto. Buscando un inca: Identidad y utopía en los Andes. Lima: Instituto de Apoyo Agrario, 1987

Haya de la Torre, Víctor Raúl. “The Apra.” The Peru Reader. History, Culture, Politics. 1995. Starn, Orin, Degregori, Carlos Iván and Robin Kirk, eds. Durham: Duke University Press, 2005. 253-258.

Huertas Castillo, Beatriz. Indigenous People in Isolation in the Peruvian Amazon. Copenhagen, IWGIA, 2004.

Kawell, Jo Anne. "The Cocaine Economy." The Peru Reader. History, Culture, Politics. 1995. Starn, Orin, Degregori, Carlos Iván and Robin Kirk, eds. Durham: Duke University Press, 2005. 253-258.

Kotovic, Misha. The Colonial Divide in Peruvian Narrative. Social Conflict and Transculturation. Brighton, UK: Sussex Academic Press, 2005.

Kristal, Efraín. Temptation of the Word. The Novels of Mario Vargas Llosa. Nashville: Vanderbilt University Press, 1998.

Lienhard, Martin. "De mestizajes, heterogeneidades, hibridismos y otras quimeras." Asedios a la heterogeneidad cultural. Mazzotti, José Antonio, U. Juan Zevallos Aguilar, eds. Philadelphia: Asociación Internacional de Peruanistas, 1996. 56- 80.

Quijano, Aníbal. Dominación y Cultura. Lo cholo y el conflicto cultural en el Perú. Lima, Mosca Azul Editores, 1980.

Ravines, Rogger, Rosalba Avalos de Matos. Atlas etnolingüística del Perú. Lima: Instituto Andino de Artes Populares del Convenio Andrés Bello, 1988. 